\title{
To transfuse or not transfuse a premature infant: the new complex question
}

\author{
Susan W. Aucott $^{1} \cdot{\text { Akhil Maheshwari }{ }^{1}}^{1}$
}

Received: 28 November 2018 / Accepted: 10 December 2018 / Published online: 16 January 2019

(c) Springer Nature America, Inc. 2019

Premature infants are a heavily transfused population [1]. Anemia is a frequently assigned diagnosis in these infants and is rooted in diverse biological factors including the physiological hypoactivity of the neonatal bone marrow exposed to increased ambient oxygen ex utero [2], insufficient erythropoietin production [3], phlebotomy losses [4], increased RBC turnover [5], rapid somatic growth, and nutritional issues such as iron deficiency $[2,6]$. Both the problem, that is the occurrence of severe anemia during critical developmental epochs, and its remedy, represented by the red blood cell (RBC) transfusions, are recognized for potential harm [7, 8]. Additionally, optimum transfusion thresholds are uncertain [9], and remain subjects of continued debate [10,11]. The care-providers' discomfort gets further accentuated because most transfusions are administered to maintain hemoglobin/hematocrit levels above predetermined, arbitrary thresholds, not to replace actual blood loss or treat symptoms clearly due to anemia.

In this month's issue of the Journal of Perinatology, Lust et al. [12]. report that very-low-birth-weight infants who received "early" RBC transfusions within 10 days after birth were more likely to develop severe retinopathy of prematurity $(\mathrm{ROP})$ [adjusted odds ratio $(\mathrm{OR})=3.8$, 95\% confidence interval (CI), 1.8-8.1]. Severe ROP was defined as disease requiring laser ablation and/or treatment with bevacizumab per standard criteria (threshold disease: stage 3 ROP with plus disease in zones I/II; high-risk prethreshold disease: any stage ROP with plus disease in zone I, stage 3 with/without plus disease in zone I, or stage 2 or 3 with plus disease in zone II). In this cohort of 1635 infants and 4464 RBC transfusions, $31 \%(1405 / 4464)$ of the transfusions

Akhil Maheshwari

akhil@jhmi.edu

1 The Charlotte R. Bloomberg Children's Center/Room 8530, 1800 Orleans Street, Baltimore, MD 21287, USA were administered within 10 days after birth. Severe ROP occurred in 115/602 (19.1\%) early-transfused infants vs. $11 / 1034(1.06 \%)$ remaining infants (OR $22,95 \% \mathrm{CI}$, 11.7-41.1, $p<0.001)$. RBC transfusions given after postnatal day 10 were not associated with severe ROP (OR 0.539; 95\% CI, 0.244-1.187).

The novel and important finding in this study is that RBC transfusions given during early neonatal period may affect the recipient differently than those given later. These observations are biologically plausible, as early introduction of adult hemoglobin can cause an inadvertent shift in the oxygen dissociation curve, increasing oxygen delivery to tissues that are still developing adaptive mechanisms to tolerate increased oxygen concentrations [13]. The endothelial toxicity of oxygen in the developing retina is wellknown [14, 15], and lends credence to these findings. While in existing studies, the link between ROP and RBC transfusions was noted in some [16, 17], it was not evident in others $[10,18,19]$; these earlier studies did not focus on the timing of transfusion.

The possibility that early RBC transfusions were a surrogate marker for higher severity of illness remains unresolved. During the early neonatal period, RBC transfusions may be given not only for severe anemia but also for other indications such as acute blood loss, hypotension, hypovolemia, to improve the oxygencarrying capacity in infants with respiratory failure, and in some centers, to replace phlebotomy losses [20]. In the present study, infants who received early transfusions were of younger gestational age and lower birth weight, had lower hemoglobins at birth, were more likely to have been exposed to chorioamnionitis, inotropes, and postnatal steroids, to undergo ductal ligation, and to have comorbidities such as necrotizing enterocolitis and bronchopulmonary dysplasia (BPD). Early-transfused infants were also more likely to receive multiple transfusions. The investigators report that the association between early transfusions and severe ROP remained identifiable even when controlling for gestational age and 
BPD. They also attempted to appraise the contribution of clinical illness by combining gestation, birth weight, postnatal steroid use, inotrope need, chorioamnionitis, PDA ligation, and BPD and controlling for this composite variable in regression analysis. However, the use of unweighted composite variables for statistical adjustment needs cautious interpretation [21].

The study has important strengths-the investigators evaluated a substantial sample size, and the single-center cohort allowed for consistency in RBC transfusion thresholds and criteria for evaluation and treatment of ROP. There are limitations of a retrospective study design, such as the possibility of bias and restricted access to information on supplemental oxygen/ventilation, storage age of transfused RBCs, detailed retinal findings (retinal hemorrhages, vascular tortuosity, etc.), and the timing of ROP surgery or bevacizumab administration. Having said this, the findings in this study are important and merit validation through secondary analysis of large existing datasets and perhaps a prospective, randomized study focused on the early neonatal period.

Unlike with RBC transfusions in convalescing premature infants, the opportunity for a clinician to withhold/defer transfusions while treating a critically ill and anemic younger premature infant on multi-modality life-support may be somewhat limited. The key may be in prevention of anemia. Unfortunately, many practice improvement steps that hold promise in reducing late transfusions, such as iron supplementation, streamlining of "surveillance" laboratory tests, and long-acting erythropoietin analogs, may not work within the first 10 days after birth. Having transfusion guidelines reduces the overall number of transfusions, but we must exercise caution before arbitrarily lowering transfusion thresholds for the sole goal of reducing transfusions. Further work is needed to establish safe thresholds to avoid unintended increase in adverse outcomes that may be related to decreased oxygen delivery to the brain, lungs, and intestine. To reduce early transfusions, emphasis should be placed on cord stripping/delayed clamping, use of placental blood for initial laboratory testing, carefully monitoring the total volume of blood drawn through central lines for pathology testing, and reducing specimen volume requirements by using point-of-care tests whenever possible and by advocating for infrastructure improvements in the hospital clinical laboratory [22]. It may also be time to re-evaluate autologous placental blood transfusions [23]. Some solutions seem visible within the line of sight, and we may be able to pick a few while awaiting further study on safe transfusion practices.

Acknowledgements This work was supported by NIH awards HL124078 and HL133022 (to AM).

\section{Compliance with ethical standards}

Conflict of interest The authors declare that they have no conflict of interest.

Publisher's note: Springer Nature remains neutral with regard to jurisdictional claims in published maps and institutional affiliations.

\section{References}

1. Strauss RG. Practical issues in neonatal transfusion practice. Am J Clin Pathol. 1997;107(4 Suppl 1):S57-63.

2. Widness JA. Pathophysiology of anemia during the neonatal period, Including anemia of prematurity. Neoreviews. 2008;9:e520.

3. Yamashita H, Kukita J, Ohga S, Nakayama H, Akazawa K, Ueda K. Serum erythropoietin levels in term and preterm infants during the first year of life. Am J Pediatr Hematol Oncol. 1994;16:213-8.

4. Rosebraugh MR, Widness JA, Nalbant D, Veng-Pedersen P. A mathematical modeling approach to quantify the role of phlebotomy losses and need for transfusions in neonatal anemia. Transfusion. 2013;53:1353-60.

5. Kuruvilla DJ, Widness JA, Nalbant D, Schmidt RL, Mock DM, An $\mathrm{G}$, et al. Estimation of adult and neonatal RBC lifespans in anemic neonates using RBCs labeled at several discrete biotin densities. Pediatr Res. 2017;81:905-10.

6. Bateman ST, Lacroix J, Boven K, Forbes P, Barton R, Thomas $\mathrm{NJ}$, et al. Anemia, blood loss, and blood transfusions in North American children in the intensive care unit. Am J Respir Crit Care Med. 2008;178:26-33.

7. dos Santos AM, Guinsburg R, de Almeida MF, Procianoy RS, Leone CR, Marba ST, et al. Red blood cell transfusions are independently associated with intra-hospital mortality in very low birth weight preterm infants. J Pediatr. 2011;159:371-6. e371-373

8. Valieva OA, Strandjord TP, Mayock DE, Juul SE. Effects of transfusions in extremely low birth weight infants: a retrospective study. J Pediatr. 2009;155:331-337 e331.

9. Christensen RD, Carroll PD, Josephson CD. Evidence-based advances in transfusion practice in neonatal intensive care units. Neonatology. 2014;106:245-53.

10. Bell EF, Strauss RG, Widness JA, Mahoney LT, Mock DM, Seward VJ, et al. Randomized trial of liberal versus restrictive guidelines for red blood cell transfusion in preterm infants. Pediatrics. 2005;115:1685-91.

11. Transfusion of Prematures Trial (TOP). ClinicalTrials.gov Identifier: NCT01702805. http://clinicaltrials.gov/ct2/show/NCT01702805

12. Lust C, Vesoulis Z, Jackups Jr. R, Liao S, Rao R, Mathur AM. Early red cell transfusion is associated with development of severe retinopathy of prematurity. J Perinatol 2018; epub ahead of print 20 November 2018; https://doi.org/10.1038/s41372-018-0274-9

13. De Halleux V, Truttmann A, Gagnon C, Bard H. The effect of blood transfusion on the hemoglobin oxygen dissociation curve of very early preterm infants during the first week of life. Semin Perinatol. 2002;26:411-5.

14. Bhandari V, Choo-Wing R, Lee CG, Zhu Z, Nedrelow JH, Chupp GL, et al. Hyperoxia causes angiopoietin 2-mediated acute lung injury and necrotic cell death. Nat Med. 2006;12:1286-93.

15. Yan X, Managlia E, Liu SX, Tan XD, Wang X, Marek C, et al. Lack of VEGFR2 signaling causes maldevelopment of the intestinal microvasculature and facilitates necrotizing enterocolitis in neonatal mice. Am J Physiol Gastrointest Liver Physiol. 2016;310:G716-25. 
16. Akkoyun I, Oto S, Yilmaz G, Gurakan B, Tarcan A, Anuk D, et al. Risk factors in the development of mild and severe retinopathy of prematurity. J AAPOS. 2006;10:449-53.

17. Slidsborg C, Jensen A, Forman JL, Rasmussen S, Bangsgaard R, Fledelius HC, et al. Neonatal risk factors for treatment-demanding retinopathy of prematurity: a Danish National Study. Ophthalmology. 2016;123:796-803.

18. Brooks SE, Marcus DM, Gillis D, Pirie E, Johnson MH, Bhatia J. The effect of blood transfusion protocol on retinopathy of prematurity: a prospective, randomized study. Pediatrics. 1999;104(3 Pt 1):514-8.

19. Kirpalani H, Whyte RK, Andersen C, Asztalos EV, Heddle N, Blajchman MA, et al. The Premature Infants in Need of Transfusion (PINT) study: a randomized, controlled trial of a restrictive (low) versus liberal (high) transfusion threshold for extremely low birth weight infants. J Pediatr. 2006;149:301-7.
20. Carson JL, Guyatt G, Heddle NM, Grossman BJ, Cohn CS, Fung MK, et al. Clinical practice guidelines from the AABB: red blood cell transfusion thresholds and storage. JAMA. 2016;316: 2025-35.

21. Becker W, Saisana M, Paruolo P, Vandecasteele I. Weights and importance in composite indicators: closing the gap. Ecol Indic. 2017;80:12-22.

22. Carroll PD, Widness JA. Nonpharmacological, blood conservation techniques for preventing neonatal anemia-effective and promising strategies for reducing transfusion. Semin Perinatol. 2012;36:232-43.

23. Sarin K, Chauhan S, Bisoi AK, Hazarika A, Malhotra N, Manek P. Use of autologous umbilical cord blood transfusion in neonates undergoing surgical correction of congenital cardiac defects: a pilot study. Ann Card Anaesth. 2018;21:270-4. 